\title{
Bioethics of military performance enhancement
}

\author{
Maxwell Mehlman
}

School of Law, Case Western Reserve University, Cleveland, Ohio, USA

\section{Correspondence to}

Professor Maxwell Mehlman, School of Law, Case Western Reserve University, Cleveland, Ohio 44106, USA; mjm10@ case.edu

Received 26 November 2018 Revised 12 February 2019 Accepted 14 March 2019

Published Online First 29 April 2019
Check for updates

(c) Author(s) (or their employer(s)) 2019. No commercial re-use. See rights and permissions. Published by BMJ.

To cite: Mehlman $\mathrm{M}$

$J$ R Army Med Corps

2019:165:226-231.

\section{ABSTRACT}

Biological interventions to improve performance, such as amphetamines, have a long history of military use, and in the future may include more advanced biotechnologies. This article discusses the ethics of using biomedical enhancements in the military. The article begins by describing the distinction between biomedical enhancements and interventions intended to prevent, treat or mitigate disease. It then sets forth three principles to guide the ethical use of bioenhancements - proportionality, paternalism and fairness. The article applies these principles to concerns raised by military bioenhancement: safety, fairness in access to military reward, carryover effects to civilian life, whether service members can be ordered to use bioenhancements and when they may be permitted to do so voluntarily.

As military operations become increasingly technological, services are searching for ways to enhance the performance of the most fragile component, the human combatant. This article focuses on biomedical enhancement, that is, enhancement achieved by the use of drugs and other types of biotechnology. (Other ways to enhance performance include mechanical assistance such as exoskeletons and brain-computer interfaces.) The article presents an overview of the subject and the author's recommendations. ${ }^{1}$

\section{WHAT COUNTS AS BIOMEDICAL ENHANCEMENT?}

A working definition of a biomedical enhancement is 'an intervention that employs medical and biological technology to improve performance, appearance, or capability besides what is necessary to achieve, sustain or restore health'. 2 Since an enhancement, by this definition, does not aim to prevent, treat or mitigate the effects of a disease or disorder, immunisation, which improves individuals' immune systems, would not qualify as an enhancement. Similarly, a drug that improves cognitive function in service members with below-normal cognitive ability would not be considered an enhancement. But a pharmacological agent that improved cognitive function in someone with a cognitive deficit to such a degree that the individual exceeded population norms for cognitive functioning clearly would qualify as an enhancement. An intervention also might be regarded as an enhancement if it improved the cognition of someone with normal cognition to start with, even though the resulting cognitive performance remained within population norms.

The concept of normality is itself elusive, however. In some cases, it refers to the frequency with which a trait or capability occurs within a population. In regard to height, the convention is to regard individuals who are more than two SD below
Key messages

The use of biomedical enhancements such as stimulants has a long history in the military and may involve more advanced biotechnologies in the future.

- The ethical use of bioenhancements in the military is governed by three principlesproportionality, paternalism and fairness.

- Before ordering or permitting the use of bioenhancements, commanders must consider what is known and uncertain about the risks and benefits to the user, the unit and the mission.

- Commanders also must consider whether performance aided by bioenhancement is worthy of reward and what impact it may have on civilians.

the mean height of the population as being of short stature. ${ }^{3}$ In other circumstances, what is considered normal may have no relationship to the population distribution of a trait. Normal eyesight is deemed to be $20 / 20$, but only about $35 \%$ of adults have $20 / 20$ vision without some form of correction. ${ }^{4}$ (The 20/20 standard of normality stems from an eye chart created by a 19th-century physician; 20/20 vision means a person can read a character of a certain size (approximately three-eighths of an inch high) on the chart from 20 feet away.) Standards of normality also may vary from place to place and time to time, and can be expected to change if the use of enhancements increases. Furthermore, the concepts of disease and disorder themselves may be hard to pin down. Before 1973, the American Psychiatric Association regarded homosexuality as a mental disorder. ${ }^{5}$ Finally, there is a tendency to regard more and more health states as diseases and more and more interventions as treatments.

In short, the distinction between health-oriented and enhancement interventions will not always be clear, and invariably there will be borderline cases. The difficulty of clearly identifying what counts as an enhancement complicates the task of determining the conditions, if any, in which it would be ethical to use enhancements in the military. Nevertheless, the above working definition is sufficient to allow some conclusions to be drawn about the appropriate use of enhancement in the military.

\section{HISTORICAL USES OF MILITARY BIOENHANCEMENT}

Military bioenhancement is not new. In a sense, military training is a form of bioenhancement, in that a major goal is to improve physical and mental 
capabilities beyond those that the service member possesses on enlistment. More exotic forms of bioenhancement also have a long history of use. Amphetamines were administered widely to American, German, British and other forces in World War II, and again to US service members in Korea, Vietnam, and the wars in Kuwait, Iraq and Afghanistan. ${ }^{6-8}$

In 1991, the Air Force Chief of Staff, General Merrill A McPeak, banned the use of amphetamines because, in his words, 'Jedi Knights don't need them'. 'The ban lasted until 1996, when Chief of Staff John Jumper reversed the policy when missions were being flown in Eastern Europe. ${ }^{10}$ In 2002, the Air Force was dispensing $10 \mathrm{mg}$ of amphetamines for every four hours of flying time for single-pilot fighter missions longer than eight hours and two-pilot bomber missions longer than 12. Asked why military pilots were permitted to use amphetamines when they were prohibited by commercial airlines, Colonel Peter Demitry, chief of the Air Force Surgeon General's Science and Technology division, explained: When a civilian gets tired, the appropriate strategy is to land, then sleep. In combat operations when you're strapped to an ejection seat, you don't have the luxury to pull over'. 10

In 2007, the US Defense Advanced Research Projects Agency (DARPA) announced a goal of 'making soldiers 'kill-proof' by, for example, enabling them 'to bring to battle the same sort of capabilities that nature has given certain animals', and by developing a supernutritional pill that, in DARPA's words, would permit 'continuous peak performance and cognitive function for 3 to 5 days, 24 hours per day, without the need for calories'. 11 In 2008, a report by JASON, a group of scientific advisors to the US Department of Defense (DoD), discussed several types of biomedical enhancements, including the potential use of a class of compounds called ampakines to enhance cognition, ${ }^{12}$ and another report in 2010 outlined an ambitious plan to employ genomic technologies to enhance 'health, readiness, and performance of military personnel'. ${ }^{13}$

\section{BIOETHICAL PRINCIPLES IN THE MILITARY}

Military bioenhancement raises several ethical issues. First, under what circumstances is it ethical to require service members to use biomedical enhancements? Second, under what circumstances is it ethical to invite service members to use biomedical enhancements? Third, under what circumstances is it ethical to forbid service members to use biomedical enhancements?

As discussed more fully in an earlier article, ${ }^{14}$ the core values in civilian life of individualism, equality, self-rule and freedom of action are reflected in the bioethical principles put forth in the Belmont Report, namely beneficence, respect for persons and justice. ${ }^{15}$ Applying these principles, civilians should never be required to use bioenhancements against their will, and competent, fully informed individuals should be free to decide for themselves whether or not to use them, except under limited circumstances where their use can be forbidden, such as when it would foster unfair competition (eg, doping in sports), when it would harm third persons (eg, alleged overaggressiveness from steroids) or when it would violate social norms (eg, use of illegal drugs).

The military has a different set of core values, however, namely selflessness, the duty to obey orders, accountability and the obligation to look out for the welfare of one's subordinates. ${ }^{16}$ The well-being of individual service members is still important, but ethically it can be over-ridden in order to promote the welfare of the unit, the success of the mission and the needs of the state. As Anthony Hartle explains, the primary purpose of the military is to maintain 'the security of the state'; therefore, 'members of the [military] profession subordinate personal welfare to the welfare of the nation' ${ }^{15}$ Furthermore, he explains, if 'the requirements of a particular mission, itself reasonably conceived, are detrimental to the welfare of the individual soldier, the duty of mission accomplishment comes first' ${ }^{15}$ Accomplishing the mission in turn requires subordinating individual interests to the well-being of the unit; as the US DoD asserted when it petitioned the Food and Drug Administration (FDA) to waive the requirement of informed consent when troops are given drugs and vaccines, 'the safety of other personnel in a soldier's unit' outweighs 'the soldier's personal preference'. ${ }^{17}$ As Samuel P Huntington stated in his classic treatise The Soldier and the State, 'the military ethic is basically corporative in spirit. It is fundamentally anti-individualistic, ${ }^{18}$

The bioethical principles that govern the military therefore differ from those that apply in civilian life. The civilian principle of beneficence, with its focus on individual well-being, does not align well with the military core value that subordinates the welfare of the individual warfighter to the needs of the unit, mission and state. Yet promoting the welfare of the individual warfighter is itself a core military value. These competing values can be reconciled by invoking ethical principles that the international community has developed to determine when it is ethical to impose a risk of harm on persons other than one's own troops, the principles of just warfare (jus ad bellum), ${ }^{19}$ military necessity and the concept of proportionality embodied in jus in bello. ${ }^{20}$ Applying these principles, a biomedical risk can be imposed on one's own troops, first, only when it is necessary, ${ }^{21}$ that is, when no less risky alternative is available to accomplish the mission. ${ }^{22}$ The mission sought to be accomplished also must have a legitimate military objective ${ }^{20}$; it would be unethical, for example, to seek to enrol a warfighter as a subject in a risky medical experiment to develop a banned form of torture or solely to benefit a private drug company. Finally, the nature and degree of the risk must be proportionate to the military advantage that is sought; the more important the objective, the greater the risk that ethically may be imposed. For the sake of brevity, these maxims will be combined in a bioethical principle of proportionality.

The principle of proportionality in military bioethics requires that the risks and benefits be known as much as possible. In the US Army, this is part of 'Composite Risk Management' (CRM), which, as described in Army Field Manual 5-19, entails identifying hazards and assessing them in terms of severity and probability. ${ }^{23}$ Proportionality in military bioethics incorporates two other norms of military life. First, judgements about whether a risk is proportional must be made at the appropriate level of command; the greater the risk, the higher the level of command that must make the decision. As Army Field Manual 5-19 states, 'Make risk decisions at the appropriate level. As a decisionmaking tool, CRM is only effective when the information is passed to the appropriate level of command for decision'.22 Second, commanders who impose risks on warfighters are accountable and subject to punishment if their orders impose disproportionate risks.

The nature and amount of biomedical risk that may be imposed on a warfighter depend on a number of considerations. One is the expected benefit, if any, to the warfighter. The US Army introduced a clotting agent, factor VII, into clinical practice in Iraq in 2004 before it was fully tested, which later revealed safety problems, such as an increased risk of blood clots that could cause strokes ${ }^{24}$ and a lack of efficacy. ${ }^{25}$ Therefore, it might be proportionate to use this unproven agent for seriously wounded soldiers, but not for those who suffered more minor, 
non-life-threatening wounds. Another consideration is whether the nation is at war or at peace. ${ }^{26}$ The DoD relied on this distinction, for example, to justify giving combat troops protective or therapeutic agents without their consent during wartime. ${ }^{27[}$

Finally, a risk might be proportionate for combat troops but disproportionate for non-combat troops. For example, the risk from an agent to protect against nerve gas might be proportionate for troops mounting an attack but not for those holding a quiet section of the line or far from the front.

Bioethics seeks to maximise the benefits of biomedical technology by protecting individuals from undue harm. In civilian bioethics, competent individuals can exercise their autonomy to protect themselves, such as by refusing to use a particular treatment. As discussed earlier, however, service personnel have little autonomy; the duty to obey orders and the command culture that it fosters restrict their freedom to make voluntary choices. This in turn limits their ability to protect themselves, such as by withholding their consent to exposure to a biomedical risk. In civilian bioethics, persons in this situation would be deemed to have diminished autonomy and their welfare should be protected by others. The same is true in the military, but whereas in civilian life the persons charged with guarding the well-being of persons with diminished autonomy can be physicians, family members, legal guardians or judges, in the military it is the responsibility of the service member's superiors. In view of the lack of autonomy in the military, it therefore makes sense to downplay the civilian emphasis on voluntary choice reflected in the principle of 'respect for persons' by substituting the principle of paternalism.

Combining the principles of paternalism and proportionality, a duty must be imposed on commanders to ensure that the biomedical risks that they impose on their subordinates are proportionate. These twin principles also guide privacy and confidentiality: commanders have a duty to protect their subordinates' privacy and confidentiality except when it is outweighed by military necessity. Finally, commanders have a duty to protect service members' dignity by avoiding exposing them to biomedical risks that humiliate or demean them. ${ }^{28}$

Some commentators, including the Presidential Advisory Committee on Gulf War Veterans' Illnesses ${ }^{29}$ and the Advisory Committee on Human Radiation Experiments, ${ }^{22}$ suggest that the voluntary nature of military service in the USA can restore a large measure of warfighter autonomy if prospective enlistees are informed of the biomedical risks to which they might be subjected in the service; if they wish to avoid those risks, they can simply decline to enlist. ${ }^{30}$ This notion of 'anticipatory consent' cannot replace the principle of paternalism, however. Describing with specificity the number and types of biomedical risks that enlistees might encounter would be difficult if not impossible. Describing them generally (eg, 'you could be asked to serve in risky medical experiments or given experimental agents without your consent') is unlikely to provide sufficient knowledge of risks and benefits to support truly informed consent. Moreover, it may not be possible to anticipate future types of risks at the time of enlistment.

While the voluntary nature of military service cannot solve the problem of the lack of service members' autonomy, it does emphasise the importance of following the principles of military bioethics, since some service members may be able to opt out of their service commitments if they feel that they are being exposed to undue biomedical risks. This was demonstrated by the actions of certain troops in response to the imposition of mandatory anthrax vaccination by the US DoD. According to a congressional report, 'the bulk of vocal resistance to the AVIP [Anthrax Vaccine Immunization Program] has arisen in ... Reserve and National Guard units .... Those service members have more options than active duty personnel. If they conclude the anthrax vaccine poses more risk than benefit to their civilian and military careers, they can resign, or seek a transfer to a non-mobility position. Many have done so. ....31

The third principle of military bioethics is fairness, which is analogous to the principle of justice in civilian bioethics. Fairness may sound like an odd principle in the military in terms of exposure to risk; the risk of injury or death is hardly 'fair', varying widely depending on the branch of service, rank, location and job. ${ }^{32}$ Nevertheless, it is appropriate to hold that fairness in military bioethics prohibits commanders from imposing risks on a subgroup of subordinates in a discriminatory manner, or on personnel who are less able to bear them than others, such as physically weaker members of a unit. The principle of fairness also means that biomedical risks should not be imposed as punishment for bad behaviour.

In some cases, the fairness principle may seem to require troops to give their consent to undertaking a biomedical risk. The argument for consent is especially strong when there is a high probability of an especially significant risk that is imposed on the few. Michael Gross argues that service persons must consent to bearing risks that are impossible to distribute equally when the risks are 'overwhelming' or 'extreme'. ${ }^{28}$ The report of the Advisory Committee on Human Radiation Experiments gives the example of test pilots. $^{22}$

In summary, the principles of proportionality and paternalism allow commanders to impose biomedical risks on a subset of subordinates only when doing so is required by the nature of the mission. In other cases, if the risk is severe enough, the subordinates should be asked to give their consent. In view of the lack of autonomy within the military, however, consent cannot fulfil the self-protective function expected of it in civilian life. Therefore, a requirement of consent can never over-ride the principles of paternalism and proportionality in the military. In other words, in some circumstances, commanders may impose biomedical risks on a subset of subordinates only with their consent, but the commanders still remain responsible if the risk is disproportionate in view of the benefits or imposed without due regard for their subordinates' well-being.

\section{CONCERNS RAISED BY MILITARY BIOENHANCEMENT}

The use of bioenhancements by the military raises several basic concerns: safety, potentially unfair impacts on promotion and assignment, carryover effects into and from civilian life, whether service members can be ordered to use or participate in research on enhancements, and how to handle self-administered bioenhancements.

\section{Safety}

The term 'bioenhancement' is broad in scope, and arguably includes numerous interventions that are relatively low-tech and safe if done properly, such as exercise and nutrition. However, the term also covers higher tech approaches such as pharmacological agents, which can raise greater safety issues. It is important to understand that virtually anything that we do to our bodies may have health and safety risks. The question therefore is not whether a bioenhancement comes with health risks, but whether the risks are outweighed by the benefits.

Consider stimulants. The 2008 JASON report mentioned earlier stated that 'the most immediate human performance factor in military effectiveness is degradation of performance under stressful conditions, particularly sleep deprivation'. ${ }^{12}$ 
Hence, in combat, stimulants may be critical to personal and unit survival and to the success of the mission. (Some even say that one of the reasons that the Union won the American Civil War is that its soldiers had coffee, while thanks to the Union blockade, Confederate troops did not). ${ }^{33}$

At the same time, the most widely used stimulants in the military, amphetamines, have known adverse effects, and can even be lethal. The military therefore must be careful to balance the health hazards of bioenhancements against their benefits. As noted earlier, the benefit of improved performance to the individual may also yield benefits to the unit, the mission and the state. It is up to commanders to determine how to weigh and compare these different types of benefit, and to decide if they are proportional to the risks to service members using the bioenhancements.

It also is important to realise that bioenhancements may create risks for third parties as well as users. Amphetamines were blamed in part for the accidental deaths of Canadian ground troops in 2004 in Afghanistan from a munition dropped by a US fighter-bomber. ${ }^{7}$ (This incident is noteworthy because the pilots may have been required to take the amphetamines in order to be permitted to fly combat missions from distant bases in Europe.)

Finally, the foregoing discussion assumes that the health effects of bioenhancements are well known, so that commanders and military health personnel can make reasoned decisions about whether the benefits outweigh the risks. But this is frequently not the case. There are very few studies, for example, on the safety and efficacy of long-term use of anabolic steroids by healthy individuals. Moreover, service members may use bioenhancements that are not prescribed or supplied by the military, and about which there is little reliable information concerning their ingredients or their ingredient strength. A 2017 report, for example, found that an average of $67 \%$ of active-duty service members in all branches of the US military used dietary supplements such as multivitamins, multiminerals, protein/amino acids, combination products and herbal substances. ${ }^{34}$ Moreover, there may be ethical, legal and practical obstacles to studying bioenhancements, such as difficulties in obtaining test samples of controlled substances or concerns about testing potentially dangerous drugs in healthy subjects.

Consequently, in determining whether the risks of enhancement use are outweighed by the benefits, commanders must take into account what is known about the risks and benefits, and what is not known, and consider how command decisions should be made in light of the uncertainties.

\section{Fairness}

Superior performance in the military is rewarded by promotions, commendations and choice assignments. If bioenhancement contributes to superior performance, should the performance be rewarded, and if so, how?

A similar issue arises in connection with the use of performance enhancements in sports, generally referred to as 'doping'. The prevailing view is that athletes should not be rewarded for accomplishments made with the aid of doping. This is obvious if doping is against the rules, but begs the question of whether or not doping should be against the rules. Reasons for prohibiting doping in sports include that (1) doping can harm athletes; (2) doping replaces effort and therefore successes are unearned; (3) doping is unfair, since, if any athletes do it, all must in order to remain competitive; (4) doping is self-defeating, since if all athletes do it, none gain a competitive advantage; (5) doping corrupts the role model that athletes represent to society and especially to youths; and (6) athletic efforts made with the aid of doping are 'inauthentic', in that baseball on steroids, for example, is not, in some sense, truly 'baseball'. 35

None of these objections seem persuasive in the military, so long as the risks to users and third parties are deemed proportionate to the overall benefits. The reason is that improvements in performance in sports do not yield any social benefit, with the dubious exception that the greater fan interest that they stimulate may make the sports more lucrative. In the military, on the other hand, improved performance can save lives, lower the risk of injury and reduce the costs of accomplishing missions.

Still, the question remains of how the use of bioenhancements in the military should affect rewards. If service members are ordered to use enhancements, then it could seem unfair to deprive them of accompanying service benefits, especially if the enhancements may create significant health risks for the user. As noted earlier, however, individuals should not be ordered to bear extra risks for illegitimate or discriminatory reasons.

\section{Civilian carryover effects}

Some members of today's military, such as reservists, members of the National Guard called to active duty, and base personnel and remote combatants such as drone operators who live with their families, may straddle military and civilian life. Military enhancements therefore may affect performance in civilian roles. ${ }^{36}$ For example, enhanced service members might gain advantages in sports or intellectual competitions with civilians. If the military enhancements are not available to civilians and the civilians are unaware that the service members they are competing with are enhanced, the service members' advantage could be deemed unfair, especially when the stakes are high. One solution might be to require service members to disclose their enhancement use prior to competing with civilians, but this may compromise secrecy and security. Another factor that must be borne in mind is that, if enhancements improve performance in civilian life, the law can take that into account in evaluating the reasonableness of risk-creating behaviours of service members and veterans. For example, automobile drivers who have superior abilities, such as better-than-normal vision or quicker reaction times, are judged on the basis of those abilities if they are sued following an accident, rather than on the abilities of average members of the population.

Additional issues arise if the effects of the enhancements persist after individuals leave the military. For example, civilians could regard enhanced veterans as having an unfair advantage. Yet the prospect of persisting postdischarge enhancement could be a recruiting incentive. Society as a whole must decide if persisting enhancement benefits are ethically acceptable. At the same time, some enhancements may have lingering negative effects, such as making some people regard users as physically unattractive. If the effects of unsightly enhancements can be readily reversed, then members of the military should be given that option before they leave the service. If the effects are difficult or impossible to reverse, then this is an additional factor for commanders to consider in determining if an order to use enhancements is proportional.

In addition, military technologies migrate to the civilian sector, and military behaviour can trigger civilian backlash, such as the controversy over interrogation techniques. Although they operate according to a different set of bioethical principles, military decision-makers therefore must take into consideration how their choices impact the civilian society that the military serves and protects. 
Finally, to what extent should military use of bioenhancements be constrained by civilian rules? Anabolic steroids in the USA, for example, are Schedule III controlled substances that can only be purchased legally by prescription, and most states prohibit doctors from prescribing them for enhancement purposes. Yet the relevant rules in the US military only prohibit the use of steroids for undefined 'wrongful' purposes, and random drug testing for steroids or unit sweeps are prohibited. ${ }^{37}$ It is unclear what purposes are 'wrongful', and therefore unclear when commanders legally can order troops to use anabolic steroids or prohibit them from doing so.

\section{Mandatory use}

The previous discussion considered whether commanders may order subordinates to use enhancements that are illegal for civilian use. But that begs the question of whether commanders can order personnel to use enhancements at all, rather than having to ask them for consent. Military personnel typically are not asked for their permission when told to do something, and they cannot refuse a lawful order, even one that places them in physical danger, without risking punishment. It does not seem that an order to use biomedical enhancements is so different from other types of orders that a different rule should apply, so long as the order is consistent with the ethical principles described earlier.

In the USA, a different answer applies to whether commanders can order service members to serve as human subjects in research studies to determine the safety and efficacy of bioenhancements. DoD and service policies state that researchers must obtain informed consent before military personnel may be enrolled as research subjects, ${ }^{38}$ and that superiors may not 'influence' the decisions of their subordinates in this regard, and may not even be present when informed consent is being sought. ${ }^{39}$

A final issue is whether warfighters can be ordered to use biomedical enhancements that have not gone through or completed testing for safety and efficacy. This issue arose with the distribution of pyridostigmine bromide and botulinum toxoid vaccine to troops during the Gulf War, and with the DoD's Anthrax Vaccine Immunization Program, which began in 1998. These products were given to troops to protect against chemical and biological weapons, but while they were approved for other indications, the FDA had not approved them for these purposes, and therefore they were being used 'off-label'. Ultimately, Congress stepped in and decided that troops could be required to use products for unapproved purposes only if a waiver of informed consent was issued by the President ${ }^{40}$ or under an Emergency Use Authorization granted by the FDA during a national emergency. ${ }^{41}$

\section{Self-enhancement}

As noted earlier, a substantial percentage of US service members use dietary supplements, at least in part to enhance performance. Special operations forces have the highest rates of use, at $76 \% .^{34}$ It is unknown how many employ other forms of bioenhancement, such as steroids, human growth hormone and erythropoietin used by athletes.

In keeping with the principle of paternalism, commanders have an obligation to protect the health of service members, including protecting them from their own voluntary decisions to use harmful substances. Moreover, if individual decisions to use bioenhancements give them advantages that may lead to military rewards, this may raise concerns similar to fairness concerns about doping in elite sports. To combat the use of prohibited enhancements, these sports employ draconian, highly intrusive drug testing programmes. Given the benefit to the state from successful military operations, a better approach for the military might be to conduct research to identify types of bioenhancement that are sufficiently safe and effective to be permissible, and to educate service members about those that should be avoided. Moreover, special operations forces in particular have been accorded greater latitude than other units in decisions about personal appearance and weaponry, which might justify greater leeway in the use of bioenhancements, consistent with the needs of the unit and mission.

\section{CONCLUSION}

Bioenhancements can improve service members' performance, which can promote safe and efficient mission accomplishment. At the same time, they present safety and fairness concerns. Command decisions about their use must conform to appropriate principles of military bioethics, namely proportionality, paternalism and fairness, to ensure that the benefits of bioenhancements outweigh the risks.

Funding Funding for this article was provided by US Department of Health and Human Services, National Institutes of Health and National Human Genome Research Institute 1R03HG006730-01.

Competing interests None declared.

Patient consent for publication Not required.

Provenance and peer review Not commissioned; externally peer reviewed.

\section{REFERENCES}

1 Mehlman MJ, Lin P, Abney K. Enhanced Warfighters: risk, ethics, and policy (Greenwall Foundation 2013) 2013

2 Juengst ET. "What does enhancement mean?". In: Parents E, ed. Enhancing human traits: ethical and social implications. Washington, DC: Georgetown University Press, 1998: 48-69.

3 Wheeler $\mathrm{P}$, Bresnahan $\mathrm{K}$, Shephard $\mathrm{B}$, et al. Criteria for determining disability in infants and children: short stature. AHRQ evidence report summaries summary. Rockville, MD: Agency for Health Care Research and Quality, 2003.

4 Johnson T. What is 20/20 vision? University of lowa Hospitals \& Clinics. Available: https://www.uihealthcare.org/2column.aspx?id=225702

5 Meyer IH, Prejudice MIH. Prejudice, social stress, and mental health in lesbian, gay, and bisexual populations: conceptual issues and research evidence. Psychol Bull 2003:129:674-97.

6 Rhonda C, Caldwell J, Cornum K. Stimulant use in extended flight operations. Airpower J 1997:XI:53-8

7 Schlesinger R. Defense cites stimulants in "friendly fire" case. Boston Globe 2003;4.

8 Caldwell JA, Caldwell JL, Lynn Caldwell J. Fatigue in military aviation: an overview of US military-approved pharmacological countermeasures. Aviat Space Environ Med 2005:76(7 Suppl):(39-51.

9 Shanker T, Duenwald D. Threats and responses: bombing error puts a spotlight on pilots' pills. New York Times 2003;19.

10 Hart L. Use of 'go pills' a matter of 'life and death,' Air Force avows, L. A. Times, 2003 Available: http://articles.latimes.com/2003/jan/17/nation/na-friendly17 [Accessed 8 Feb 2019].

11 Moreno JD. Mind wars: brain research and national defense. Washington, D C: Dana Press, 2006.

12 JASON.JSR-07-625. Human performance; 2008

13 JASON.JSR-10-100. The \$100 Genome: Implications for DoD; 2010: 1.

14 Mehlman MJ, Corley S. A framework for military bioethics. Journal of Military Ethics 2014;13:331-49.

15 National Commission for the Protection of Human Subjects of Biomedical and Behavioral Research. The Belmont report: ethical principles and guidelines for the protection of human subjects of research, 1979. Available: http://ohsr.od.nih.gov/ guidelines/belmont.html [Accessed 6 Jun 2019].

16 Hartle AE. Moral issues in military decision making, Lawrence. KA: University Press of Kansas, 2004: 59-173.

17 House Committee on Government Reform. House Committee on government reform. The Department of defense anthrax vaccine immunization program: unproven force protection, H. R 2000:54-5.

18 Huntington SP. The soldier and the state: the theory and politics of Civil-Military relation. Cambridge. 64. MA: Harvard University Press, 1957. 
19 Chomeau JB, Rudolph AC. Intelligence collection and analysis: dilemmas and decisions. In: Gaston JC, Hietala JB, eds. Ethics \& National Defense: The Timeless Issues. Washington, DC: National Defense University Press, 1993: 123.

20 Graham DE. Cyber threats and the law of war. J. of National Sec. L. and Pol 2010;4

21 Howe EG. Dilemmas in military medical ethics since 9/11. Kennedy Inst Ethics 2003;13:175-88.

22 . Advisory Committee on human radiation experiments: final report. Washington, DC US Government Printing Office; 1995.

23 Department of the Army. FM 5-19 composite risk management. 2006:1-2.

24 Berenson A. Army's aggressive surgeon is too aggressive for some, N. Y. Times, 2006. Available: http://www.nytimes.com/2007/11/06/health/06prof.html?pagewanted=all [Accessed 11 Feb 2019].

25 Little R. Army medicine: untested in battle, Baltimore sun, 2009. Available: https:// www.baltimoresun.com/news/nation-world/bal-te.militarymed29mar29-story.htm [Accessed 11 Feb 2019].

26 Frisina ME. Medical ethics in military biomedical research. In: Textbooks of military medicine: military medical ethics. 547. Washington, DC: Office of the Surgeon General, US Army, 2003.

27 US Food and Drug Administration. Informed consent for human drugs and biologics; determination that informed consent is not feasible. fed. reg 1990;55

28 Gross ML Bioethics and Armed Conflict. Moral dilemmas of medicine and war. Cambridge, MA: MIT Press, 2006: 101-11.

29 (1997) Presidential Advisory Committee on Gulf War Veterans' IIInesses, Final Report, 1997. Available: https://gulflink.health.mil/gwvi/toc-f.html [Accessed 11 Feb 2019].
30 Fitzpatrick WJ, Zwanziger LL. (2003) defending against biochemical warfare: ethical issues involving the coercive use of investigational drugs and biologics in the military. J Phil Sci 2003;3.

31 Committee on Government Reform. The Department of defense anthrax vaccine immunization program: unproven force protection, H. R. Rep. no 2000.

32 Buzzell E, Preston SH. Mortality of American troops in the Iraq war. Popul Dev Rev 2007:33:555-66

33 Yesalis CE, Bahrke MS. History of doping in sport. International Sports Studies 2001;24.

34 Knapik J, Austin D, Throne E, et al. Dietary supplement use in all United States military services. Faseb J 2017:31.

35 Mehlman MJ, Banger E, Wright M. Doping in sports and the use of state power, St. Louis University Law Review 2006:50:15-73.

36 Eisenstein N, Naumann D, Burns D, et al. Left of bang interventions in trauma: ethical implications for military medical prophylaxis. J Med Ethics 2018:44:504-8.

37 U S. Department of Defense, department of defense instruction (DoDI) No. 1010.16, military personnel drug abuse testing program, 2017. Available: http://www.esd.whs. mil/Portals/54/Documents/DD/issuances/dodi/101016p.pdf [Accessed 11 Feb 2019].

38 McManus J, Mehta SG, McClinton AR, et al. Informed consent and ethical issues in military medical research. Acad Emerg Med 2005;12:1120-6.

39 U S. Department of Defense, department of defense instruction (DoDI) No. 3216.02 protection of human subjects and adherence to ethical standards in DoD-Supported research, glossary, 2011. Available: https://fas.org/irp/doddir/dod/i3216_02.pdf [Accessed 11 Feb 2019].

4010 U.S.C. $\$ 1107(f) 1999$.

41 Project BioShield act of 2004. 